\title{
STUDI SANITASI LEMBAGA PEMASYARAKATAN KELAS IIB DIKABUPATEN CILACAPTAHUN 2017
}

\author{
Dwi Sundaryati Apri rahayu'), Agus Subagiyo ${ }^{2)}$ \\ Jurusan Kesehatan Lingkungan, Politeknik Kesehatan Kemenkes Semarang, \\ Jl.Raya Baturaden KM 12 Purwokerto, Indonesia
}

\begin{abstract}
Abstrak
Lembaga Pemasyarakatan atau LAPAS adalah tempat untuk melakukan pembinaan terhadap narapidana dan anak didik permasyarakatan di Indonesia.Tujuan penelitian ini adalah untuk mengetahui kondisi sanitasi di Lembaga Pemasyarakatan Kelas IIB Cilacap. Jenis penelitian ini adalah deskriptif dengan melakukan pengamatan, pengukuran dan wawancara, hasilnya diolah dan disajikan dalam bentuk narasi dan tabel. Hasil penilaian sarana sanitasi Lembaga Pemasyarakatan Kelas IIB Cilacap sudah memenuhi syarat.Hasil presentase sanitasi di Lembaga Pemasyarakatan kelas IIB Cilacap sudah memenuhi syarat. Banguanan di Lembaga Pemasyarakatan Kelas IIB Cilacap dari kondisi lantai terbuat dari bahan kuat (terbuat dari keramik), dinding (terbuat dari bahan batu bata atau beton), atap (kuat, tidak bocor), pintu (dapat dibuka, ditutup dan dikunci dengan baik,terbuat dari bahan kayu atau besi), hasil pengukuran suhu $28{ }^{\circ} \mathrm{C}$ sampai $30^{\circ} \mathrm{C}$ dan kelembaban $50 \%$ sampai $51 \%$, air bersih dan air minum dengan pemeriksaan E-coli 0 per $100 \mathrm{ml}$ sampel dan secara fisik air tidak berbau,tidak berasa dan tidak bewarna, sampah ditampung ditempat sampah tertutup,tidak ada genangan air, tidak ada pemisah sampah organik dan anorganik. Simpulan bahwa Sanitasi Lembaga Permasyarakatan Kelas IIB Cilacap masuk dalam katagori baik namun ada beberapa aspek yang belum memenuhi syarat dari pengumpulan sampah.Saran agar petugas LAPAS memberikan penyuluhan tentang pengolahan sampah.
\end{abstract}

Kata kunci:Sanitasi Lembaga Pemasyarakatan;kesehatan lingkungan

\begin{abstract}
[Title: sanitation study of iib class preparation in the cilacap regency of 2017]Penitentiary or LAPAS is a place to conduct guidance on prisoners and prison students in Indonesia. Based on preliminary survey conducted by researchers still found aspects of sanitation facilities that have not been eligible in the Class IIB Cilacap LAPAS. The purpose of this research is to know the condition of sanitation in Class IIB Penitentiary Cilacap. The type of this research is descriptive by doing observation, measurement and interview, the result is processed and presented in the form of narration and table. The results of the assessment of sanitation facilities Calss IIB Penitentiary Cilacap already qualified. The results of sanitation percentage in Class IIB Cilacap prison already meet the requirements. Building in Class IIB Penitentiary Cilacap from floor condition made of strong material (made of ceramic), wall (made of brick or concrete),roof (strong,not leak),door (can be opened,closed and locked well,Made of wood or iron), the results of temperature measurement $28{ }^{\circ} \mathrm{C}$ to $30^{\circ} \mathrm{C}$ and humidity $50 \%$ to $51 \%$, clean water and driking water with E-Coli 0 per $100 \mathrm{ml}$ sampel and physical water is odorless, no taste and not colores, garbage collected in closed garbage, no puddles,no organic and inorganic waste separators. The conclusion that Class IIB Cilacap Sanitation is in good category but there are some aspects that are not yer qualified from garbage collection. Suggestion that officers of LAPAS give counseling abaut waste processing
\end{abstract}

Keywords:Sanitation Peniteriary; environmenthal health 


\section{Pendahuluan}

Undang-Undang Nomor 36 Tahun 2009 tentang Kesehatan, menjelaskan pada pasal 5 yang mengatakan bahwa setiap orang mempunyai hak yang sama memperoleh akses atau sumber daya dibidang kesehatan dan setiap orang mempunyai hak dalam memperoleh pelayanan kesehatan yang aman, bernutu dan terjangkau. Pernyataan tersebut bearti setiap orang mempunyai hak untuk kesehatan tidak terkecuali para narapida maupun para petugas atau karyawan yang bekerja di Lapas Kelas II B cilacap tersebut.

Peraturan Pemerintah Republik Indonesia Nomor 32 Tahun 1999 tentang Syarat dan Tata Cara Pelaksanaan Hak Warga Binaan Pemasyarakatan menyatakan bahwa pelayanan kesehatan di lembaga permasyarakatan adalah upaya promotif, preventif, kuratif, dan rehabilitative di bidang kesehatan bagi narapidana dan anak didik permasyarakatan di lembaga permasyarakatan.

Undang-Undang Nomor 12 Tahun 1995 tentang Pemasyarakatan pasal 1 urutan ke tiga menjelaskan bahwa Lembaga Pemasyarakatan atau yang sering disebut LAPAS adalah tempat yang digunakan untuk melaksanaan pembinaan Narapidana dan Anak Didik Pemasyarakatan. Pada Lapas terdapat beberapa anak didik pemasyarakatan diantaranya: Anak Pidana merupakan anak yang berdasarkan keputusan pengadilanmenjalani pidana dilapas anak paling lama sampai berumur 18 tahun, Anak Negara merupakan anak yang berdasarkan keputusan pengadilan diserahkan Negara untuk di didik dan ditempatkan di Lapas anak paling lama sampai berumur 18 tahun, Anak Sipil merupakan anak yang atas permintaan orang tua atau walinya yang memperoleh penetapan pengadilan untuk dididik di Lapas anak paling lama sampai berumur 18 tahun.

Dari hasil survei pendahuluan peneliti di Lembaga Pemasyarakatan Kelas IIB Cilacap, didapatkan data sebagai berikut :

1) Menurut pengelola ruang kesehatan di Lembaga Pemasyarakatan bahwa hasil laporan bulanan oleh petugas kesehatan terdapat 10 narapida yang menderita penyakit kulit. Selain penyakit kulit juga terdapat penyakit gastrogeneratif atau penurunan fungsi sistem pencernaan dan penyakit degeneratif atau penyakit akibat penurunan fungsi tubuh.

2) Kondisi sanitasi Lembaga Pemasyarakatan belum memenuhi syarat.

3) Perilaku narapidana yang kurang mendukung pola hidup sehat, misalnya mandi hanya 1 kali sehari, tidak membersihkan tempat tidur setelah digunakan.

\footnotetext{
${ }^{*}$ E-mail: dwicilacap2@gmail.com

${ }^{* *}$ E-mail: agusgiyo@yahoo.co.id
}

Berdasarkan latar belakang tersebut maka penulis tertarik untuk mengadakan penelitihan yang berjudul "Studi Sanitasi Lapas Kelas IIB Cilacap Di Kabupaten Cilacap Tahun 2017 “

\section{Bahan dan Metode}

Pengambilan data/ sampel dilakukan di Lembaga Pemasyarakatan Kelas IIB Cilacap.Subyek dalam penelitian ini yaitu Sanitasi Lapas Kelas II B cilacap dengan sarana penyediaan air bersih, sarana air limbah, sarana pengolahan sampah.

Sumber data adalah data primer yang diperoleh dari Sipil atau pegawai Lapas dan Cheklis dan kuesioner.Data sekunder diperoleh dari poliklinik lapas.

Jenis Penelitian yang digunakan adalah Penelitian Deskriptif, tujuannya untuk memperoleh gambaran tentang kondisi sarana sanitasi yang ada di lapas kelas II B Cilacap tahun 2017.

\section{Hasil dan Pembahasan \\ 3.1 Data Umum}

LembagaPemasyarakatan(LAPAS) adalah tempat untuk melaksanakan pembinaan narapidana dan anak didik pemasyarakatan.LAPASKelasII B Cilacap terletak di JL. Kerinci No. 120 Cilacap, Kabupaten Cilacap. Lembaga Pemasyarakatan Kelas IIB Cilacap ini jarakanya berdekatan dengan institusi terkait yang berada di Kabupaten Cilacap diantara lain:

a. Kejaksaan Negeri Kabupaten Cilacap yang jaraknya $10 \mathrm{~m}$

b. Pemerintah Daerah Kabupaten Cilacap jaraknya $70 \mathrm{~m}$

c. Polres Cilacap jaraknya 7km, RSUD Cilacap jaraknya $2 \mathrm{~km}$

d. Pengadilan Negeri Cilacap jaraknya 4km

e. Pemadam Kebakaran jaraknya3km

f. Kodim dengan jarak 500m

Lembaga Pemasyarakatan memiliki kondisi bangunan secara infrastruktur yang meliputi luas bangunan yaitu $3.311 \mathrm{~m}^{2}$ dan luas tanah yaitu $5.521 \mathrm{~m}^{2}$, secara fisik meliputi luas kantor yaitu $1758.87 \mathrm{~m}^{2}$, kamar hunian $1164.33 \mathrm{~m}^{2}$, dan luas bengkel kerja yaitu $90 \mathrm{~m}^{2}$. Lembaga Pemasyarakatan Kelas IIB Cilacap ini memiliki jumlah karyawan sebanyak 52 orang dan memiliki jumlah narapida untuk narapidana lakilaki sebanyak 340 orang dan narapidana perempuan sebanyak 11 orang.Sarana dan Prasarana di Lembaga Pemasyarakatan Kelas II B Cilacap.

a. Gedung atau Kantor

Gedung atau kantor yang terdapat di Lembaga Permasyarakatan Kelas II B Cilacap terdiri dari : 
1) Kantor Kepala Lapas yang memiliki luas bangunan yaitu $5 \mathrm{~m}$ x $4 \mathrm{~m}$

2) Kantor Kepala Subag TU memiliki luas bangunan yaitu $4 \mathrm{~m} \times 3 \mathrm{~m}$

3) Kantor Kepala Sie Binadik (pembinaan dan pendidikan) memiliki luas bangunan yaitu $5 \mathrm{~m}$ x 3,5 m

4) Kantor Kepala PLP (pengamanana lembaga permasyarakatan) memiliki luas bangunan yaitu $3,5 \mathrm{~m} \times 5 \mathrm{~m}$

5) Kantor Kepala Sie Kamtib (keamanan dan ketertiban) memiliki luas bangunan yaitu $3,5 \mathrm{~m} \times 3 \mathrm{~m}$

b. Disamping itu fasilitas bangunan lain yang terdapat di Lembaga Pemasyarakatan Kelas II B Cilacap terdiri dari :

1) Perkantoran yang memiliki luas bangunan yaitu $5 \mathrm{~m} \mathrm{x} 4 \mathrm{~m}$

2) Bimbingan kerja memiliki luas bangunan yaitu $22 \mathrm{~m}$ x $5 \mathrm{~m}$

3) Tempat ibadah yang terdiri dari masjid dengan luas bangunan $17 \mathrm{~m} \times 6 \mathrm{~m}$ dan tempat kebaktian untuk non muslim dengan luas bangunan 3,5m x 2,5m

4) Aula (tempat olahraga) dengan luas bangunan yaitu $22 \mathrm{~m} \times 3 \mathrm{~m}$

5) Poliklinik dengan luas bangunan yaitu $9 \mathrm{~m} \times 3 \mathrm{~m}$

c. Kamar Hunian yang terdapat di Lembaga Pemasyarakatan Kelas II B Cilacap terdiri dari :

1) Blok hunian WBP (warga binaan pemasyarakatan) yang terdiri dari :

a. Blok I terdiri dari 18 ruangan dengan luas bangunan $2 \mathrm{~m} \times 1,5 \mathrm{~m}$ dan diisi oleh 303 orang

b. Blok II terdiri dari 4 ruangan denga luas bangunan $2 \mathrm{~m} \times 1,5 \mathrm{~m}$ dan diisi oleh 60 orang

2) Blok hunian wanita yang terdiri dari :

a. Blok I diisi oleh 5 orang dengan luas bangunan $6 \mathrm{~m} \times 5 \mathrm{~m}$

b. Blok II diisi oleh 6 orang dengan luas bangunan $6 \mathrm{~m} \times 5 \mathrm{~m}$

Lembaga Pemasyarakatan Kelas II B Cilacap memiliki kapasitas penghuni sebanyak 351 orang dan Untuk jumlah penghuni yang berjenis kelamin perempuan sebanyak 11 orang dan untuk laki-laki sebanyak 340 orang.

Jumlah pegawai di Lembaga

Pemasyarakatan Kelas II B Cilacap berjumlah 49 karyawan dengan jumlah karyawan laki-laki 39 Orang dan jumlah karyawan perempuan 10 orang.

\section{Data Khusus}

a. Pengolahan Sampah

Pengolahan sampah di Lembaga Pemasyarakatan Kelas IIB Cilacap belum memenuhi syarat dalam pengumpulan sampah organik dan sampah anorganik. Sesuai dengan Peraturan Pemerintah Republik Indonesia Nomor 18 Tahun 2012 Tentang pengolahan sampah rumah tangga dan sampah sejenisnya pada pasal 17, menyebutkan bahwa sampah tersebut pengelompokan menjadi 5 jenis sampah yaitu: sampah mengandung bahan berbahaya dan beracun (B3), sampah yang mudah terurai, sampah yang dapat digunakan kembali, sampah yang dapat didaur ulang, dan sampah lainnya. Sesuai dengan Departemen Kesehatan Republik Indonesia Direktorat Jenderal PPM \& PL (2001, hal.11) menjelaskan bahwa penampungan atau pewadahan sampah untuk sampah yang cepat membusuk dan berbau sebelum ditampung di tempat sampah agar dimasukkan dalam kantong kedap air dan diikat. Menurut PERDA KABUPATEN PAKPAK BHARAT Nomor 8 Tahun 2014 Tentang pengolahan sampah menjelaskan pada pasal 4 bahwa sampah digolongkan berdasarkan sumbernya yaitu sampah rumah tangga, sampah sejenis sampah rumah tangga, dan sampah spesifik. Tempat sampah yang ada Lembaga Permasyarakatan Kelas IIB Cilacap setiap hari dikosongkan oleh petugas dan dibawa ke Tempat pengumpulan sampah sementara (TPS) dan sampah yang di TPS diangkut oleh tugas kebersihan Kabupaten Cilacap.

b. Saluran Pembuangan Air Limbah

Pembuangan air limbah yang berasal dari kamar mandi dan dapur menggunakan saluran tertutup, kedap air dan air limbah dari sumur disalurkan kesungai yang berada dibelakang Lapas, air limbah dari kamar mandi disalurkan ke septic tank yang berada dibelakang masing-masing blok. Sesuai dengan Surat Edara Pemasyarakatan Nomor PAS-373.PK.01.07.01 Tahun 2016 Tentang Sanitasi dan Kesehatan Lingkungan LAPAS,LPKA,RUTAN DAN CABANG RUTAN, bahwa saluran air limbah tertutup, tidak menimbulkan bau, dan jarak sumber pencemar dengan sumber air bersih $10 \mathrm{~m}$. Menurut Departemen Kesehatan Republik Indonesia Direktorat Jenderal PPM \& PL (2001, hal.17), bahwa syarat limbah cair disalurkan kedalam saluran tertutup, tahan 
terhadap gigitan binatang pengerat atau tikus dan dapat mengalir dengan lancar, saluran air limbah cair yang berasal dari kamar mandi harus dilengkapi dengan jeruji atau kasa yang dapat mencegah keluar masuknya serangga seperti kecoa, lalat dan tikus dan limbah yang berasal dari kamar mandi harus menggunakan sistem leher angsa dan dialirkan ke septik tank.

c. Sarana kamar mandi dan jamban

Semua blok baik untuk blok laki-laki maupun blok wanita dilengkapi dengan 1 kamar mandi dengan keadaan kamar mandi bersih, tidak berbau, kran air mengalir dengan baik, terdapat 1 jamban leher angsa, terdapat bak mandi dengan lantai kuat, tidak licin, dan tidak ada genangan air. Sesuai dengan Direktorat Jenderal PPM dan PL tahun 2000 persyarat kesehatan yang memenuhi syarat yaitu tidak berbau, tidak licin, lantai dan dinding kedap air, dan tidak ada genangan air. Sesuai dengan Keputusan Menteri Republik Indonesia Nomor 1045 Tahun 2002 Tentang Persyaratan Kesehatan Lingkungan Kerja Perkantoran dan Industri, bahwa syarat kesehatan kamar mandi dan jamban yaitu Kamar mandi harus dibersihkan minimal 2 kali sehari dan kamar mandi dan jamban tidak menjadi tempat berkembangbiaknya serangga dan tikus.

d. Pengendalian Vektor

Di Lembaga Pemasyarakatan Kelas IIB Cilacap dalam penyimpanan bahan makan, peralatan makan dan peralatan masak masih belum sesuai karena masih diletakan atau disimpan dalam wadah yang terbuka, dalam hal tersebut sangat cepat terkontaminasi oleh vektor dan apabila digunakan tidak dengan dibersihkan terlebih dahulu akan menyebabkan gangguan kesehatan. Sesuai dengan surat edaran nomor PAS-373.PK.01.07.01 tahun 2016 tentang sanitasi dan kesehatan lingkungan LAPAS,LPKA,RUTAN DAN CABANG RUTAN bahwa perlu dilakukan upaya berkala dalam memusnahkan jentik nyamuk di lingkungan lapas, LPKA, rutan dan cabang rutan dengan cara menggubur, menguras dan menutup tempat tempat penyimpanan air, dapat melakukan pengasapan atau fogging untuk membunuh nyamuk, perlu diperhatikan untuk menjaga kesehatan bahan makan, minum atau air bersih dan lingkungan dapur serta alat yang digunakan dari lalat, kecoa dan tikus, serta tidak untuk memelihara atau membawa binatang peliharaan kedalam lingkungan lapas. Direktorat Jenderal PPM dan PL tahun 2002 Tentang pedoman pengendalian, menjelaskan bahwa pencegahan terhadap vektor yaitu menutup lubang-lubang atau cela-cela agar kecoa tidak masuk dalam ruangan, menyimpan bahan makanan dan minuman jadi pada tempat tertutup. Melakukan penyemprotan ruangan, memasang perekat lalat, penangan sampah dengan baik dan benar untu mencegah bersarangnya lalat, dan mencegah masuknya kecoa dengan cara pemeriksaan ruangan atau cela-cela disekitar pintu atau jendela untuk mencegah masuknya kecoa. (Chasan SudjainKusnadi,2006,hal. 64 - 72)

e. Penyediaan air bersih

Sumber air bersih yang digunakan di Lembaga Pemasyarakatan kelas IIB Cilacap memiliki 2 sumber yaitu sumber dari air sumur dan sumber dari air PDAM. Sesuai dengan Surat edaran Nomor PAS373.PK.01.07.01 Tahun 2016 Tentang Sanitasi dan Kesehatan Lingkungan LAPAS,LPKA,RUTAN DAN CABANG RUTAN air yang tersedia diakses selama 24 jam dan kapasitas yang digunakan 100 liter/orang/hari yang digunakan untuk kebutuhan mandi, cuci,kakus dan membersihan ruangan. Sumber air bersih ini di distribusikan ke semua blok-blok menggunakan pompa air yang dimasukan ke tandor

air.Sumberairbersihyangdigunakansebaiknya di tes laboratorium minimal sebanyak 1 kali dalam 6 bulan.Kualitas air secara fisik memenuhi syarat kesehatanantaralaintidakberbau,tidakberwarn adantidakberasa. Untuk uji laboratorium untuk sampel air PDAM seperti E-coli 0 per $100 \mathrm{ml}$ sampel, TDS85,0 mg/l dan Sisa Chlor0,1 mg/l. sampel air sumur jumlah Ecoli $=0$ per $100 \mathrm{ml}$ sampel, TDS $=181 \mathrm{mg} / \mathrm{l}$, Sisa Cholr $=0,2 \mathrm{mg} / \mathrm{l}$ dan $\mathrm{pH}$ stik untuk air sumur adalah hasil 7 sedangkan untuk air PDAM hasilnya 6. Untuk kuantitas air digunakan yaitu 100 liter/orang/hari selama 24 jam. Sesuai dengan Peraturan Menteri Kesehatan Nomor 492 Tahun 2010 Tentang persyaratan kualitas air minum memenuhi syarat. 
Tabel 4.3 pengukuran debit air sumur

\begin{tabular}{llll}
\hline Pengukuran & $\begin{array}{l}\text { Waktu } \\
\text { (T) } \\
\text { detik }\end{array}$ & $\begin{array}{l}\text { Volume } \\
\text { (V) } \\
\text { liter }\end{array}$ & Hasil \\
\hline Pengukuran 1 & 06.82 & $\begin{array}{l}1000 \\
\mathrm{ml}\end{array}$ & $0.0022 \mathrm{~m} / \mathrm{s}$ \\
Pengukuran 2 & 06.57 & $\begin{array}{l}1000 \\
\mathrm{ml}\end{array}$ & $0.0024 \mathrm{~m} / \mathrm{s}$ \\
Pengukuran 3 & 07.10 & $\begin{array}{l}1000 \\
\mathrm{ml}\end{array}$ & $0.0023 \mathrm{~m} / \mathrm{s}$ \\
Pengukuran 4 & 06.81 & $\begin{array}{l}1000 \\
\mathrm{ml} \\
1000\end{array}$ & $0.225 \mathrm{~m} / \mathrm{s}$ \\
Pengukuran 5 & 07.28 & $\begin{array}{l}0.0022 \mathrm{~m} / \mathrm{s} \\
\mathrm{ml}\end{array}$ & \\
\hline
\end{tabular}

Sumber: Primer

Tabel 4.4 pengukuran debit air PDAM

\begin{tabular}{llll}
\hline Pengukuran & $\begin{array}{l}\text { Waktu } \\
\text { (T) detik }\end{array}$ & $\begin{array}{l}\text { Volume } \\
\text { (V) liter }\end{array}$ & Hasil \\
\hline Pengukuran 1 & 02.07 & $1000 \mathrm{ml}$ & $\begin{array}{l}0.0078 \\
\mathrm{~m} / \mathrm{s}\end{array}$ \\
Pengukuran 2 & 02.51 & $1000 \mathrm{ml}$ & $\begin{array}{l}0.0058 \\
\mathrm{~m} / \mathrm{s}\end{array}$ \\
Pengukuran 3 & 03.23 & $1000 \mathrm{ml}$ & $\begin{array}{l}0.0049 \\
\mathrm{~m} / \mathrm{s}\end{array}$ \\
Pengukuran 4 & 03.38 & $1000 \mathrm{ml}$ & $\begin{array}{l}0.0047 \\
\mathrm{~m} / \mathrm{s}\end{array}$ \\
& & & 0.0045 \\
Pengukuran 5 & 03.42 & $1000 \mathrm{ml}$ & $\begin{array}{l}0 . \mathrm{s} \\
\end{array}$
\end{tabular}

Sumber: Primer

Untuk kebutuhan sehari-hari di Lembaga Pemasyarakatan dengan kebutuhan air bersih 100 l/orang/hari dan kebutuhan air minum 2 l/orang/hari bagi penguhi lapas.

f. Penyediaan air minum

Untuk kuantitas air minum yaitu 2 liter/orang/hari dan kualitas air secara fisika yang diuji oleh Bapak Paiman, Bapak Suradi dan Bapak Taufik air bersih memenuhi syarat tidak berbau, tidak berasa dan tidak bewarna.Pemeriksaan laboratorium jumlah E-coli= 0 per $100 \mathrm{ml}$ sampel, TDS= $67,1 \mathrm{mg} / \mathrm{l}$ dan Sisa Cholr $=0,1 \mathrm{mg} / \mathrm{l}$. Sesuai dengan Peraturan Menteri Kesehatan Nomor 492 Tahun 2010 Tentang persyaratan kualitas air minum bahwa air minum yang aman bagi kesehatan apabila memenuhi persyaratan fisika mikrobiologi, kimiawi dan radioaktif yang dimuat dalam parameter wajib dan parameter tambahan. Air minum dikatakan sehat dapat memenuhi persyaratan air minum yaitu tidak berbau, tidak bewarna dan tidak berasa. (Sutrisno, Totok, 2010. Hal.24)

g. Sanitasi Ruang Tahanan

Tabel 4.5 pengukuran suhu dan kelembaban ruangan

\begin{tabular}{llll}
\hline No & \multicolumn{1}{c}{$\begin{array}{c}\text { Tempat } \\
\text { Pengukuran }\end{array}$} & $\begin{array}{c}\text { Hasil } \\
\text { Pengukuran } \\
\text { Suhu }\end{array}$ & $\begin{array}{c}\text { Hasil } \\
\text { Pengukuran } \\
\text { Kelembaban }\end{array}$ \\
\hline 1. & Ruang Kesehatan & $30{ }^{\circ} \mathrm{C}$ & $51 \%$ \\
2. & $\begin{array}{l}\text { Ruang Sel Kamar } \\
\text { Pengasingan }\end{array}$ & $29{ }^{\circ} \mathrm{C}$ & $50 \%$ \\
3. & $\begin{array}{l}\text { Ruang Blok } \\
\text { Wanita (BW) }\end{array}$ & $30{ }^{\circ} \mathrm{C}$ & $50 \%$ \\
4. & $\begin{array}{l}\text { Ruang Kantor } \\
\text { K.Sie.Administrasi }\end{array}$ & $31{ }^{\circ} \mathrm{C}$ & $52 \%$ \\
5. & $\begin{array}{l}\text { Ruang Masjid } \\
29\end{array}$ & $50 \%$ \\
6. & $\begin{array}{l}\text { Ruang aula } \\
\text { 7. }\end{array}$ & $\begin{array}{l}\text { Ruang bengkel } \\
\text { Kerja }\end{array}$ & $30{ }^{\circ} \mathrm{C}$ \\
8. & $\begin{array}{l}\text { Ruang } \\
\text { Perpustkan }\end{array}$ & $50 \%$ \\
\hline
\end{tabular}

Sumber: Primer

Untuk suhu dan kelembabantertinggi yang dilakukan hari Jum'at, 19 Mei 2017 pukul $08.30-10.00$ WIB terdapat kelembaban dan suhu tertinggi yaitu pada ruang Ruang Kantor K.Sie.Administrasi dengan suhu $31{ }^{\circ} \mathrm{C}$ dan untuk kelembaban yaitu Ruang Kantor K.Sie.Administrasi dan Ruangan Aula dengan kelembaban 52\%. Standar suhu dan kelembaban sesuai Peraturan Menteri Kesehatan Republik Indonesia Nomor 1077 Tahun 2011 Tentang Pedoman Penyehatan Udara Dalam Ruangan Rumah yaitu untuk suhu $18{ }^{\circ} \mathrm{C}$ sampai $30^{\circ} \mathrm{C}$ dan kelembaban $40 \%$ sampai $60 \%$ sehingga memenuhi syarat. 
Tabel 4.6 pengukuran luas ventilasi

\begin{tabular}{|c|c|c|c|}
\hline No & $\begin{array}{c}\text { Tempat } \\
\text { pengukuran }\end{array}$ & $\begin{array}{c}\text { Hasil } \\
\text { pengukuran }\end{array}$ & kriteria \\
\hline 1 & $\begin{array}{l}\text { Ruang Blok } \\
\text { Wanita(BW } \\
\text { ) }\end{array}$ & $161,2<1.190,7$ & $\begin{array}{l}\text { Tidak } \\
\text { memenuhi } \\
\text { syarat }\end{array}$ \\
\hline 2 & $\begin{array}{l}\text { Ruang } \\
\text { bengkel } \\
\text { kerja }\end{array}$ & $300>15,4$ & $\begin{array}{l}\text { Memenuh } \\
\text { syarat }\end{array}$ \\
\hline 3 & Ruang aula & $1992>640$ & $\begin{array}{l}\text { Memenuh } \\
\text { syarat }\end{array}$ \\
\hline 4 & $\begin{array}{l}\text { Ruang } \\
\text { kantor } \\
\text { K.Sie.Admi } \\
\text { nistrasi }\end{array}$ & $\begin{array}{l}375> \\
56.7\end{array}$ & $\begin{array}{l}\text { Memenuh } \\
\text { syarat }\end{array}$ \\
\hline 5 & $\begin{array}{l}\text { Ruang } \\
\text { masjid }\end{array}$ & $422.4>13.2$ & $\begin{array}{l}\text { Memenuh } \\
\text { syarat }\end{array}$ \\
\hline 6 & $\begin{array}{l}\text { Ruang } \\
\text { perpustakaa } \\
\text { n }\end{array}$ & $145.2<161.6$ & $\begin{array}{l}\text { Tidak } \\
\text { memenuhi } \\
\text { syarat }\end{array}$ \\
\hline
\end{tabular}

Sumber: Primer

Untuk pengukuran luas ventilasi masih terdapat 2 yang belum memenuhi syarat yaitu Ruang Blok Wanita ( BW ) dan Ruang Perpustakaan

Keadaan suhu ruangan dan kelembaban ruangan untuk ruang sel kamar pengasingan memperoleh $50 \%$ dan $29^{\circ} \mathrm{C}$, sedangkan untuk ruang blok wanita (BW) suhu dan kelembaban ruangan memperoleh $50 \%$ dan $30^{\circ} \mathrm{C}$. Keadaan ini memenuhi syarat menurut Peraturan Menteri Kesehatan Republik Indonesia Nomor 1077 Tahun 2011 Tentang Pedoman Penyehatan Udara Dalam Ruangan Rumah yaitu standar suhu dan kelembaban suatu ruangan yang digunakan $18^{\circ} \mathrm{C}$ sampai $30^{\circ} \mathrm{C}$ dan $40 \%$ sampai $60 \%$. Syarat kesehatan suhu dan kelembaban ruangan menurut Keputusan Menteri Republik Indonesia Nomor 1405 Tahun 2002 Tentang Persyaratan Kesehatan Lingkungan Kerja Perkantoran dan Industri yaitu standar suhu ruangan $18^{\circ} \mathrm{C}$ sampai $28^{\circ} \mathrm{C}$ dan kelembaban ruangan $40 \%$ sampai $60 \%$.

h. Sanitasi Bangunan, Kamar atau Ruangan dan Fasilitas Penunjang

Menurut Keputusan Menteri

Kesehatan Republik Indonesia No.829 Tahun

1999 Tentang Persyaratan Kesehatan

Perumahan.Bahwa untuk komponen

bangunan, kamar atau ruangan dan fasilitas penunjang sudah memenuhi syarat.Untuk lantai kedap air dan mudah dibersihkan, dinding memiliki ventilasi, kamar mandi kedap air dan mudah dibersihkan, langitlangit harus mudah dibersihkan dan tidak rawan kecelakaan. Departemen Kesehatan R.I Direktorat Jenderal PPM \& PL Tahun 2001 menjelaskan bahwa syarat bangunan yang sehat yaitu ruangan dan bangunan harus selalu dalam keadaan bersih dan tersedia fasilitas sanitasi yang memenuhi persyaratan kesehatan, ruang dan bangunan tidak memungkinkan sebagai tempat bersarang dan berkembangbiak serangga, bintang perekat dan binatang pengganggu. Untuk kontruksi lantai terbuat dari bahan yang kuat, kedap air, permukaan rata dan mudah dibersihkan.Dinding permukaan rata, warna terang dan mudah dibersihkan.Atap kuat, tidak bocor dan tidak sebagai perindukan serangga dan tikus. Untuk ventilasi setiap lubang ventilasi harus dilengkapi dengan kawat kasa untuk mencegah masuknya serangga (nyamuk dan lalat)

i. Pemeriksaan Sarana Sanitasi Berdasarkan Form Pemeriksaan

Tabel 4.7 Hasil Pemeriksaan Sarana Sanitasi Lembaga Permasyarakatan Kelas IIB Cilacap, Berdasarkan form pemeriksaan

\begin{tabular}{|c|c|c|c|c|c|}
\hline No & $\begin{array}{l}\text { Komponen } \\
\text { Pemeriksan }\end{array}$ & $\begin{array}{l}\text { Jumlah } \\
\text { hasil } \\
\text { item } \\
\text { "ya" }\end{array}$ & $\begin{array}{c}\text { Presentasi } \\
(100 \%)\end{array}$ & Katagori & Ket \\
\hline 1 & $\begin{array}{l}\text { Penyediaan } \\
\text { Air Bersih }\end{array}$ & 3 & $100 \%$ & Baik & MS \\
\hline 2 & $\begin{array}{l}\text { Jamban } \\
\text { dan } \\
\text { Kamar } \\
\text { Mandi }\end{array}$ & 5 & $100 \%$ & Baik & MS \\
\hline 3 & $\begin{array}{l}\text { Pengolahan } \\
\text { Sampah }\end{array}$ & 11 & $91 \%$ & Baik & MS \\
\hline 4 & $\begin{array}{l}\text { Saluran } \\
\text { pembuanga } \\
\text { n air limbah }\end{array}$ & 3 & $100 \%$ & Baik & MS \\
\hline 5 & $\begin{array}{l}\text { Pencegah } \\
\text { masuknya } \\
\text { vektor dan } \\
\text { binatang } \\
\text { pengganggu }\end{array}$ & 2 & $66 \%$ & Cukup & MS \\
\hline
\end{tabular}

Sumber: Primer 


\section{Kesimpulan:}

Berdasarkan penelitihan yang dilakukan pada tanggal 22 April 2017 sampai 6 Juni 2017, didapatkan kesimpulan sebagai berikut:

1. Untuk pengolahan sampah di Lembaga Pemasyarakatan Kelas IIB Cilacap sebagian besar sudah memenuhi syarat hanya untuk pengumpulan sampah antara sampah organik dan sampah anorganik masih dicampur jadi satu belum ada pemisah sampah

2. Pengolahan air limbah di Lembaga Pemasyarakatan Kelas IIB Cilacap sudah memenuhi syarat yaitu saluran air limbah tertutup, tidak menimbulkan bau, dan jarak sumber pencemar dengan sumber air bersih 10 $\mathrm{m}$.

3. Sarana kamar mandi dan jamban di Lembaga Pemasyarakatan Kelas IIB Cilacap sudah memenuhi syarat yaitu keadaan kamar mandi bersih, tidak berbau, kran air mengalir dengan baik, terdapat 1 jamban leher angsa, terdapat bak mandi dengan lantai kuat, tidak licin, dan tidak ada genangan air

4. Pengendalian vektor dan binatang pengganggu di Lembaga Pemasyarakatan Kelas IIB Cilacap belum memenuhi syarat yaitu dalam penyimpanan bahan makan, peralatan makan dan peralatan masak masih belum sesuai karena masih diletakan atau disimpan dalam wadah yang terbuka, dalam hal tersebut sangat cepat terkontaminasi oleh vektor dan apabila digunakan tidak dengan dibersihkan terlebih dahulu akan menyebabkan gangguan kesehatan.

5. Kondisi air bersih dan air minum di Lembaga Pemasyarakatan Kelas IIB Cilacap sudah memenuhi syarat yaitu air yang tersedia diakses selama 24 jam dan kapasitas yang digunakan 100 liter/orang/hari yang digunakan untuk kebutuhan mandi,cuci,kakus dan membersihan ruangan, Kualitas air secara fisik memenuhi syarat

kesehatanantaralaintidakberbau,tidakberwarnada ntidakberasa.

6. Kondisi suhu dan kelembaban ruangan di Lembaga Pemasyarakatan Kelas IIB Cilacap sudah memenuhi syarat yaitu rata-rata suhu $29^{\circ} \mathrm{C}$ sampai $31^{\circ} \mathrm{C}$ dan kelembaban $50 \%$ sampai $52 \%$

7. Kondisi bangunan, ruang atau kamar dan fasilitas pendukung di Lembaga Pemasyarakatan Kelas IIB Cilacap sudah memenuhi syarat yaitu Untuk lantai kedap air dan mudah dibersihkan, dinding memiliki ventilasi, kamar mandi kedap air dan mudah dibersihkan, langit-langit harus mudah dibersihkan dan tidak rawan kecelakaan.
SaranBagi Kepala Lembaga Pemasyarakatan Kelas IIB Cilacap :

a) Bagi petugas Lembaga Pemasyarakatan melakukan penyuluhan tentang pengolahan sampah

b) Bagi petugas Lembaga Pemasyarakatan sebaiknya melakukan uji laboratorium minimal sebanyak 3 bulan sekali untuk air bersih dan air minum agar mengetahui kualitas air yang ada di Lembaga Pemasyarakatan Kelas IIB Cilacap

c) Bagi petugas Lembaga Pemasyarakatan untuk penyimpanan bahan makan, peralatan makan dan peralatan masak sebaiknya disimpan ditempat yang tertutup agar tidak terkontaminasi oleh vektor

Saran Bagi Peneliti

Untuk penelitian selanjutnya melakukan pengecekan hygiene sanitasi makanana dan minuman yang ada di Lembaga Pemasyarakatan Kelas IIB Cilacap

\section{UcapanTerima Kasih}

Ucapan terima kasihterutama ditujukan kepada Bapak Hernowo Sugiastanto BcIP. S.Sos, selaku Kepala Lembaga Permasyarakatan Kelas IIB Cilcap, Bapak Suradi, SH, dan Bapak Taufik Imtikhani, S.IP, selaku narasumber yang telah membantu penelitian, serta Bapak dan Ibu yang selalu mendukung dan mendoakan serta memberikan kasih saying yang tulus, dan tidak lupa juga kepada teman-teman yang sudah bantuan dan masukan yang bermanfaat

\section{DaftarPustaka}

Anonim, Profil Lembaga Permasyarakatan Kelas IIB Cilacap

Departemen Kesehatan R.I 1992, penelitihan kader kesehatan lingkungan Jakarta: dirjen PPM dan PLP

Departemen Kesehatan R.I 2001, Pedoman Pelaksana Sanitasi Lingkungan Jakarta: dirjen PPM dan PL

Keputusan Menteri Kehakiman dan Hak Asasi Manusia Republik Indonesia Nomor: M.05PR.07.03 Tahun 2003 tentang Perubahan Rumah Tahanan Negara menjadi Lembaga Permasyarakatan

Keputusan Menteri Kesehatan Republik Indonesia Nomor 1405/MENKES/SK/XI/2002 tentang persyaratan kesehatan lingkungan kerja perkantoran dan industri 
Kusnadi, Chasan Sudjain, 2006. Pengendalian Vektor dan Binatang Pengganggu.Makasar: Jurusan Kesehatan Lingkungan Politeknik Kesehatan Makasar. Hal: 41-72

Menteri Kesehatan Republik Indonesia No.829/Menkes/SK/VII/1999Tentang Persyaratan Kesehatan Perumahan

PERDA KABUPATEN CILACAP Nomor 3 tahun 2011 Tentang Pengolahan Sampah dan Retribusi Pelayanan Persampahan atau Kebersihan Kabupaten Cilacap

PERDA KABUPATEN PAKPAK BHARAT PROVINSI SUMATERA UTARA Nomor 8 Tahun 2014 Tentang Pengolahan Sampah

Peraturan Menteri Kesehatan Nomor 492/MENKES/PER/IV/2010 Tentang persyaratan kualitas air minum

Peraturan Menteri Lingkungan Hidup dan Kehutanan Nomor: P.68/Menlhk/Setjen/Kum.1/8/2016 tentang baku mutu air limbah Domestik

Peraturan Menteri Kesehatan Repbulik Indonesia Nomor: $\quad$ 374/MENKES/PER/III/2010 Tentang pengendalian Vektor

Peraturan Menteri Kesehatan Republik Indonesia Nomor 1077/MENKES/PER/V/2011

Tentang Pedoman Penyehatan Udara Dalam Ruangan Rumah

Peraturan Pemerintah Republik Indonesia Nomor 32 Tahun 1999 tentang Syarat dan Tata Cara Pelaksanaan Hak Warga Binaan Pemasyarakatan

Peraturan Pemerintah Republik Indonesia Nomor 18 Tahun 2012 Tentang pengolahan sampah rumah tangga dan sampah sejenisnya
Peraturan Pemerintah Republik Indonesia Nomor 66 Tahun 2014 Tentang Kesehatan Lingkungan

Safrianto, Nugraha , 2014 , Studi Sarana Sanitasi Lembaga Permasyarakatan Kelas II A Kembangkuning Nusakambangan Cilacap tahun 2014, Karya Tulis ilmiah , Purwokwerto : Departemen Kesehatan RI Politeknik Kesehatan Semarang Jurusan Kesehatan Lingkungan Purwokerto.

Suparlan, 2012, Pengantar Pengawasan Hygine Sanitasi Tempat-Tempat Umum \& Usaha-Usaha Untuk Umum , Surabaya : Duatujuh.

Surat Edaran Permasyarakatan Nomor PAS373.PK.01.07.01 Tahun 2016 Tentang Sanitasi dan kesehatan Lingkungan Lapas, LPKA, Rutan dan cabang Rutan

Sutrisno,Totok, 2010, Teknologi Penyediaan Air bersih, Jakarta : PT Rineka Cipta

Tri Cahyono, 2014, Pedoman Penulisan Proposal Penelitihan Karya Tulis Ilmiah / Skripsi ( Edisi Revisi Ketiga ).Purwokerto : Kementerian kesehatan RI Politeknik Kesehatan Depkes Semarang Jurusan Kesehatan Lingkungan.

Undang-Undang Nomor 12 Tahun 1995 tentang Pemasyarakatan

Undang-Undang Nomor 36 Tahun 2009 tentang Kesehatan 